\title{
Clinical Trial Safety Management Plan
}

National Cancer Institute

\section{Source}

National Cancer Institute. Clinical Trial Safety Management Plan. NCI Thesaurus. Code C115755.

A proposed method to address the safety evaluations that occur for the duration of the trial. 